\title{
A FORMA DA LETRA PARA O ESTUDO DAS LETRAS: A CONDIÇÃO PARATEXTUAL DA TIPOGRAFIA
}

lara Pierro de Camargo*

RESUMO: O livro impresso de literatura tem hoje, na maioria das vezes, um design simples e funcional, isto é feito para a leitura. O design do livro pode, assim, passar despercebido pelos leitores e ser negligenciado pelos editores por sua suposta simplicidade: páginas compostas apenas com tipos. A tipografia, apesa de parecer pouco expressiva, por suas sutilezas de desenho e de sua composição, pode estabelecer relações com o texto literário e indicar o contexto histórico e cultural daquela publicação, como indicam pesquisadores da área da bibliografia e sociologia dos textos. A tipografia é portanto um poderoso paratexto da obra. Além A paratexto, seu uso pode influenciar na recepçao

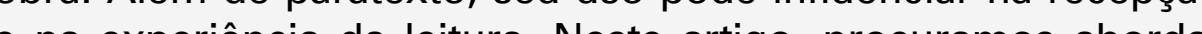
e na experiencia da leitura. Neste artigo, procuramos abordar as questoes levantadas acima e evidenciar aspectos fisicos do desenho das letras para incentivar que estudiosos da área da literatura se preocupem cada vez mais com esses elementos formais indispensáveis para a criação de um livro e a realização da escrita e da leitura.

Palavras-chave: tipografia; design do livro; paratexto.
* iaritcha@hotmail.com

Doutora pela Faculdade de Arquitetura e Urbanismo da Universidade de São Paulo (área Design).

ABSTRACT: The literature printed book has today, mostly, a simple and functional design, it means, made for reading. The book design may, therefore, many times go unnoticed by readers and be neglected by editors by its supposed simplicity: pages composed only with types. Typography, despite seems less expressive, by its subtleties of drawing and composition, may establish relations with the literary text and indicate the historical and cultural context of that publication, as indicated by researchers of bibliography and sociology of texts. Typography is, therefore, a powerful paratext. Besides paratext, its use may influence the repow ception and experience of reading. In this paper, we discuss the questions raised above and evidence the physical aspects of letter drawing to encourage researchers from the field of Literature that worry increasingly to these formal elements crucial to book creation and the act of writing and reading.

Keywords: tipografia; design do livro; paratexto. 


\section{INTRODUÇÃO}

A intenção deste artigo é apresentar a importância do design e da tipografia como paratextos, ou seja, como textos que podem auxiliar a análise textual e também a experiência do leitor em livros em prosa. A tipografia de uma página impressa deve, obviamente, proporcionar uma leitura prazerosa e não cansar o leitor, ou seja, deve ser suficientemente arejada para não aprisionar o texto entre margens diminutas ou entrelinhas pequenas, enquanto a fonte escolhida deve ser apropriada para a leitura de textos longos. Mesmo que aparentemente a página seja apenas utilitária, aspectos formais dos tipos e a forma como são compostos podem incitar sensações no leitor e, também, estabelecer relações temporais ou conceituais, isto é, semânticas, em diálogo com o texto literário.

Nesta reflexão, procuramos primeiramente apresentar questões sobre livros simples e ornamentados e os problemas causados pela Revolução Industrial, como a produção massificada e de baixa qualidade. Em sequência, discutimos a bibliografia e o paratexto, além da estética tipográfica, seguidos de um estudo de caso com quatro propostas de design de livro para um mesmo texto, os problemas relativos ao descaso no design de livros e a (suposta) ameaça dos livros digitais.

\section{APRESENTAÇÃO}

O livro físico, isto é, o objeto de páginas dobradas, refiladas e costuradas envoltas por uma capa, é suporte para vários tipos de texto, inclusive o literário. Na maioria das vezes, o design da página é adequado para cada um, como ficção, poesia, didático, informativo, infantil, arte, etc. Livros destinados à leitura contínua, como romances, apresentam, em sua maioria, leiautes simples de uma coluna composta com tipos serifados e sem ornamentos e são idealmente projetados do ponto de vista funcional, agradáveis de segurar, fáceis de ler pelo uso de tipos adequados, ${ }^{1}$ com entrelinhas e margens satisfatórias, e sem o intuito de distrair o ato de ler por meio de artifícios visuais como ilustrações e vinhetas.

Mesmo sendo comum ver livros impressos de textos em prosa com essa configuração convencional, pode-se observar hoje o esforço de algumas editoras, como a extinta Cosac Naify, Ubu, Visual Editions, na Inglaterra, ou Libros del Zorro Rojo, na Espanha, em produzir livros cujo design seja específico para aquele texto particular e não padronizado, como livros de coleção. Apesar de a aposta pelo apelo material do livro por editoras contemporâneas parecer novidade hoje, ao longo da história já foram produzidos livros ricamente decorados, ilustrados e feitos com materiais nobres e táteis como couro, madeira, pergaminho, etc. $\mathrm{O}$ design dos primeiros livros impressos simulava o estilo das obras decoradas e feitas à mão. $\mathrm{Na}$ época o livro simples e sem ornamentos não tinha o mesmo apelo, já que, antes da Revolução Industrial, os livros sempre foram obras muito valiosas, raras
1. Tipos simples e de fácil reconhecimento. Tipos muito expressivos (Display) são recomendados apenas para títulos, cartazes, etc. 
2. Bringhurst, em Elementos do estilo tipográfico (p. 45), assinala que tipos mais pesados requerem mais entrelinha: "Fontes como a Bauer Bodoni, com cor forte e eixo mais entro, precisam de multo como a Bembo, em que a cor cha a eixo se basia na escrita

3. MIDDENDORP. Shaping text, p. 22 (Tradução nossa).

4. MANGUEL. Uma história da leitura p. $160-161$. tanto pelo tempo que se levava para produzi-los quanto pela nobreza dos materiais utilizados.

O leiaute das páginas do livro em prosa simples, parecidas com a maioria das de hoje, nasceu em Veneza, entre 0 final do século XV e início do XVI, pelas mãos do editor e impressor Aldus Manutius. Ele criou um modelo portátil in-oitavo e, a partir do volume De Aetna (1495-96), de Pietro Bembo, gerou um paradigma de livro sóbrio, sem luxo, bem impresso, com margens funcionais, isto é, amplas o suficiente para que fossem seguradas pelas mãos. Manutius produziu livros para serem lidos no colo e portáteis, diferentemente de obras de grandes proporções, como eram a maioria na época, para leitura em mesas ou escrivaninhas. Além das margens, Aldus usava entrelinhas satisfatórias, ou seja, proporcionais ao tamanho do tipo e ao da coluna. ${ }^{2}$

Segundo Jan Middendorp, " "um livro como De Aetna, do cardeal Pietro Bembo, impresso na oficina de Aldus em 1495 96, não é significativamente diferente das brochuras produzidas hoje”. Manguel ${ }^{4}$ aponta a importância da empreitada de Manutius em produzir livros simples e mais econômicos:

Em 1501, confiante no sucesso de suas primeiras publicações, Aldus respondeu à demanda dos leitores produzindo uma coleção de livros de bolso in-octavo - metade do tamanho do in-quarto -, impressos com elegância e editados meticulosamente.

Para manter baixos os custos da produção, decidiu imprimir mi exemplares de cada vez, e, para usar a página de forma mais econômica, utilizou um tipo recém-desenhado, o itálico ou grifo, criado pelo talhador e fundidor de tipos Francesco Griffo, que também talhou o primeiro tipo romano no qual as maiúsculas eram menores do que as letras ascendentes (altura total) da caixa baixa, a fim de assegurar uma linha mais equilibrada. [...] O resultado foi um livro que parecia muito mais simples do que as edições manuscritas ornamentadas, aquelas que haviam sido populares durante toda a Idade Média - um volume de sobriedade elegante. O mais importante para o possuidor de uma edição de bolso de Aldus era o texto, impresso com clareza e erudição - não um objeto ricamente decorado. ${ }^{5}$

Bartram explica que os livros italianos do século XVI eram desprovidos de ornamento, o que mostra que esses outros impressores italianos seguiram o estilo aldino. Mais tarde, porém, os franceses retomaram o uso da decoração:

Os primeiros impressores italianos dispensaram muitas vezes qualquer forma de decoração. Mas, a partir da primeira metade do século XVI até meados do século XVIII, impressores franceses (que assumiram a liderança, superando os italianos), enquanto ainda trabalhavam com o conceito clássico de simetria formal, geralmente constritora, eram regidos por uma tradição diferente. Eles produziam livros que eram primariamente decorativos, mais que um meio de comunicação. ${ }^{6}$
5. MANGUEL Uma história da leitura, p. 62
6. BARTRAM. Bauhaus, modernism and the illustrated book, p. 16 (Tradução nossa). 
7. BARTRAM. Bauhaus, modernism and the illustrated book, p. 16. (Tradução nossa).

8. LYONS. Livro: uma história viva p. 9.

9. A má qualidade da composição tipográfica e da diagramaçáo pode se relacionar a problemas pours, entrelinhas, tama

do corpo da fonte em raña à

largura da coluna, uso incorreto da hifenização, margens insatisfatórias, coluna muitr

insatisfatorias, coluna muito larga página, largura da coluna muito página, largura da coluna muito espaços entre palavras criandose "rios brancos" (rivers of white) ou "caminhos de rato", escolha de família tipográfica inadequada à leitura, ocorrência de viúvas e órfãs, entre muitas outras questões tecnicas do campo do design

editorial. Observa-se que no século XIX muitos livros eram projetados sem levar em consideração

criterios básicos, como entrelinhas satisfatórias e regularidade na mancha de texto, sendo comuns muitos buracos ("caminhos de rato") no meio do texto.

10. A impressão deve ser uniforme e, com o metodo de impressão direta (tipografia) utilizado na época, se a pressão da tinta no papel não é uniforme, parte do texto fica mais claro ou mais escuro. Hoje, com a impressão offset, ainda podem existir problemas de impressão, como deslocamento do registro, impressão borrada pela umidade do papel, etc.
Entre os séculos XVI e XVIII, tanto livros simples quanto livros decorados foram feitos, porém a simplicidade parece ter começado a se tornar um estilo a partir dos impressos por John Baskerville e Giambattista Bodoni. ${ }^{7}$

Antes da Revolução Industrial, e da "revolução da leitura" recreativa no século XVIII, ${ }^{8}$ o livro era produzido de forma quase artesanal e muitos apresentavam esmero na impressão, composição, qualidade do papel e encadernação. Pelo cuidado na produção, eram objetos duráveis e até hoje sobrevivem em excelente estado de conservação. Após a Revolução Industrial, por meio de novos recursos, foram produzidas grandes tiragens de livros de péssima qualidade de materiais (papel e encadernação), composição tipográfica e leiaute ${ }^{9}$ e impressão. ${ }^{10}$

Em oposição ao livro industrializado e malfeito surgiram entre o fim do século XIX e início do XX, iniciativas que promoveram a produção e o design do livro bem feito a partir do retorno à composição com tipos móveis, em oposição à composição mecânica pela linotipo ou monotipo; uso de papel artesanal de fibra de algodão e livre de alvejantes e de $\mathrm{Ph}$ neutro em vez de papéis feitos a partir da polpa de madeira, que rapidamente tornavam-se quebradiços, oxidavam, amarelavam e emboloravam; encadernação manual com materiais nobres como o couro.

A escolha da tipografia também se alterou significativamente. Em contraponto ao emprego de tipos pesados e de alto contraste no século XIX, procurou-se usar tipos mais leves e legíveis dos séculos XV, XVI e XVII. Segundo Camargo,

Os tipos criados por Bodoni na Itália e por Didot na França tiveram muito impacto durante todo século XIX. McLean (1972: 12) aponta o uso extensivo desses tipos na Inglaterra no início do século XIX, dessa forma, não é de se estranhar que no final deste século e início do século XX tipos modernos foram perdendo sua popularidade a partir do resgate de tipos oldstyle promovido especialmente nas primeiras décadas do século $X X{ }^{11}$

Por questões anatômicas e tecnológicas, tipos antigos ou oldstyle, como podem ser chamados os estilos tipográficos do final do século XV até meados do século XVIII, são mais abertos, apresentam menos contraste entre traços grossos e finos, são mais leves e possuem características da escrita manual feita com a pena de ponta quadrada. Tipos criados a partir do século XVIII, e em especial criados no século XIX, em geral são mais racionais, não apresentam vestígios de escrita manual e possuem contraste acentuado (Figura 1).

\section{moderado acentuado}

11. CAMARGO. O livro de literatura: entre o design visível e o invisível, p. 38
EM TESE
BELO HORIZONTE
v. 22
N. 3
SET.-DEZ. 2016
CAMARGO. A forma da letra para o estudo das letras: a condição [...]
P. 11-33

FIGURA 1 - Diferenças de contraste entre Bembo (séc. XV) e Bodoni Os traços finos em proporção aos grossos possuem espessura bem menor, conferindo ao tipo o contraste
acentuado 
12. BENTON. The beauty and the book, p. 34
As iniciativas que promoveram o resgate dos bons costumes da impressão e da tipografia, uso de materiais de qualidade e design bem feito são as do Movimento das Prensas Particulares e da Fina Impressão na Europa e nos Estados Unidos, os quais produziram muitas edições de livros de literatura que, pela qualidade dos materiais utilizados, rigor no leiaute, esmero na impressão e presença de ilustrações, por enfatizarem aspectos estéticos do objeto, apontaram caminhos além da mera funcionalidade do design para o desenvolvimento do livro útil. Livros como os feitos durante o Movimento das Prensas Particulares eram planejados por renomados artistas da época.

Nos Estados Unidos, especialmente após a Primeira Guerra sobretudo na década de 1920, havia diversas casas especializadas na produção de livros finos, especiais e limitados, a partir da tradição dos livros artesanais. Essa abordagem é conhecida por fine printing (Fina Impressão). Alguns dos designers conhecidos por propagar e trabalhar com essa abordagem nos Estados Unidos são Daniel Berkeley Updike, Bruce Rogers, William Addison Dwiggins, Rudolph Ruzicka, Frederic Goudy, John Henry Nash, Edwin e Robert Grabhorn, T. M Cleland, Frederic Warde, Carl Purrington Rollins e Elmer Adler. Para Megan Benton, ${ }^{12}$ a Fina Impressão surgiu como espécie de "sacerdócio", que renovaria a produção de livros, seguindo os mais altos padrões de design e impressão.
Livros como esses, talvez pela primeira vez depois da Revolução Industrial, passaram a ser objetos cobiçados por seu valor elevado e a ser colecionados por entusiastas, tornando-se uma espécie de investimento, como joias. Muitos desses livros de literatura publicados possuem ilustrações e eles não serviam apenas para a leitura, mas também eram alvo de admiração.

$\mathrm{Na}$ contramão da proposta de algumas prensas particulares que produziram livros decorados no final do século XIX início do século $\mathrm{XX}$, alguns tipógrafos e impressores passaram a advogar pela produção de livros simples, em que a tipografia tivesse um papel funcionalista e subordinado ao texto. A ideia da tipografia como meio utilitário foi defendida, especialmente, por Beatrice Warde, em seu famoso discurso Why printing should be invisible proferido em 1930. Segundo Camargo:

Em Printing should be invisible, Warde (1956: 11-12) faz uma analogia entre a tipografia de livros (página impressa) e uma taça de cristal, estabelece um paralelo entre a taça e sua função de recipiente transparente para que se veja o conteúdo. Segundo Warde (1956: 11), a taça possui uma haste cuja função é a de ser segurada, para que se evite que impressões digitais sejam marcadas na copa, onde o vinho é colocado. Ou seja, para evitar a criação de ruídos (interferências) no recipiente 
13. CAMARGO. $O$ paradigma do design do livro "invisivel". p. 724

14. CAMARGO. $O$ paradigma do design do livro "invisivel". p. 726 que alterem a visão do líquido. Essa haste é comparada às margens do livro, cuja função é evitar que os dedos do leitor se apoiem sobre o texto. Para a autora, taças de vinho e a composição tipográfica em livros devem ser ambas transparentes. ${ }^{13}$

Warde preocupava-se especialmente pela boa composição do livro, pela legibilidade e funcionalidade do design. Esse discurso ficou muito conhecido por propor que a tipografia devesse ser invisível, ou seja, que não devesse chamar a atenção. Essa ideia foi abraçada especialmente por designers modernistas que almejavam a funcionalidade e a neutralidade do design e da tipografia. O conceito de invisibilidade proposto por ela aparentemente, deixa pouca margem para a experimentação tipográfica da página impressa. No entanto, como observa Camargo, Warde em outros textos, como em On the choice of type faces, defende a sutil personalidade de fontes tipográficas e que mínimas variações estéticas na tipografia apresentam certas conotações: "Há, então, certa contradição sobre o idea da "invisibilidade" nos discursos de Warde, uma vez que ela considera que variações tipográficas dão um "tom" diverso ao texto impresso". ${ }^{14}$ Dessa maneira, se a sutileza da tipografia é expressiva, a neutralidade se torna uma impossibilidade.

Se movimentos como o das Prensas Particulares e o da Fina Impresão chamaram a atenção de leitores, colecionadores, críticos, tipógrafos e impressores sobre a materialidade, qualidade e expressividade do livro de literatura, talvez o livro simples, sem ornamentos e padronizado tenha tido efeito inverso, deixando o suporte em segundo plano e subordinando ao texto e à leitura.

\section{PARATEXTOS: A IMPORTÂNCIA DO DESIGN E DA}

\section{TIPOGRAFIA PARA A ANÁLISE TEXTUAL}

Pode ser mais fácil perceber e defender a importância do estudo da materialidade do livro decorado e produzido com materiais especiais. No outro extremo, pode ser difícil notar ou mesmo procurar estudar a materialidade através de elementos sutis, como a tipografia, como fez D. F. McKenzie na área de estudo da bibliografia.

Diversos autores da área da bibliografia e da literatura destacam a importância do projeto gráfico para a construção de significados. Gérard Genette ${ }^{15}$ classifica o projeto gráfico de um livro como paratexto. Paratextos são definidos como textos que acompanham um texto e podem ou não estar no mesmo volume. Grande parte dos paratextos é de natureza verbal, como títulos, prefácios, resenhas, mas há também os não verbais, que correspondem à estrutura física do volume (materiais, acabamento e tipografia):

[...] quase todos os paratextos considerados serão de ordem textual ou, pelo menos, verbal: títulos, prefácios, entrevistas, 
16. GENETTE. Paratextos editoriais, p. 14.

17. GENETTE. Paratextos editoriais, p. 21

18. Genette usa o termo "bibliotecnia", porém, nesse contexto, poder-se-ia usar o termo "design editorial".

19. MCKENZIE. Bibliografia y sociología de los textos. assim como enunciados [...], mas compartilhando o estatuto linguístico do texto. No mais das vezes, portanto, o paratexto é um texto: se ainda não é o texto em si, pelo menos já é texto. Mas deve-se pelo menos ter em mente o valor paratextua que outros tipos de manifestações podem conter: icônicas (as ilustrações), materiais (tudo o que envolve, por exemplo, as escolhas tipográficas, por vezes muito significativas, na composição de um livro). ${ }^{16}$

Genette amplia a noção de paratexto, incluindo os elementos materiais do livro, como formato, capa, página de rosto e composição tipográfica: "a capa, a página de rosto e seus anexos; e da realização material do livro, cuja execução depende do impressor, mas cuja decisão é tomada pelo editor, em eventual conjunto com o autor: escolha do formato, do papel, da composição tipográfica, etc." ${ }^{17}$

O autor não aprofunda a discussão sobre o projeto gráfico como paratexto para não invadir o campo de outras disciplinas, ${ }^{18}$ mas abre caminho para isso ser explorado por outros pesquisadores.

D. F. McKenzie ${ }^{19}$ aponta que a configuração visual dos textos produz diferentes significados de acordo com seu contexto, assim, a análise textual pode ser atrelada à do projeto gráfico. Para comprovar essas diferenças, ele compara duas frases de William Congreve: a publicada na versão original (1710) e em um contexto de citação feito por outros autores (1946) e composta de forma diferente. Após a comparação, verifica que a composição tipográfica tem uma função expressiva:

Tenho agora de voltar a considerar o caso particular dos textos impressos. Ao fazê-lo, a questão em concreto que desejo colocar é se as formas materiais dos livros, os elementos verbais dos signos tipográficos, a disposição do próprio espaço, têm uma função expressiva ao transmitir significado e se seu estudo constitui propriamente uma incumbência bibliográfica. ${ }^{20}$

Nessa passagem, McKenzie legitima a pesquisa da configuração visual e material do texto aos estudos da bibliografia Ao dizer que os elementos gráficos apresentam uma "função expressiva”, confere pertinência aos estudos concernentes à relação entre o texto e sua configuração material.

[...] é possível fazer leituras cheias de significado a partir dos signos tipográficos tanto como dos verbais, pois estas têm a ver com decisões editoriais relativas a como se deve reproduzir um texto, assim como uma leitura de tais signos bibliográficos pode repercutir gravemente em nosso juízo sobre a obra de um autor. [...] Todas as leituras são características de suas circunstâncias temporais, podendo, ao menos parcialmente, ser reconstruídas a partir das formas materiais do texto, constituindo essas diferenças de leituras uma história
20. MCKENZIE. Bibliografia $y$ sociología de los textos, p. 34 (Tradução nossa). 
21. MCKENZIE. Bibliografia y sociología de los textos, p. 36 (Tradução nossa).

\section{MCKENZIE. Bibliografia $y$} sociología de los textos, p. 42 (Tradução nossa).

23. MCGANN. Black Riders: the visible language of modernism. muito reveladora. Nenhuma história do livro pode ignorar questões como o que pensaram que estavam fazendo os escritores ao compor textos, os impressores e livreiros ao projetá-los e publicá-los, ou os leitores ao criar sentido a partir deles. ${ }^{21}$

McKenzie $^{22}$ verifica a importância da configuração visua de um texto referente a determinado contexto cultural, porém é possível tomar como ponto de partida a importância do leiaute de um livro como reflexo de diferentes formas como é possível ler um texto, já que cada edição pode apresentar configurações visuais diferentes.

Assim como em McKenzie, a preocupação com o projeto gráfico de um livro como elementos significativo pode ser observada nos textos de Jerome McGann,, ${ }^{23}$ que se interessa pelas condições materiais em que o livro é produzido, apresentando exemplos da relação entre vários escritores, como William Morris, Yeats e Pound, com a produção e a impressão de seus textos, como indicações de preocupação formal e estética, além de explicar a importância de movimentos de impressão como o das Prensas Particulares para o desenvolvimento da literatura modernista do final do século XIX e início do XX.

McGann aborda a importância da investigação do texto com foco em condições materiais e históricas e explica a importância do estudo da textualidade fundamentado pela paleografia, bibliografia e sociologia dos textos. Ele propõe o estudo das variações das estruturas materiais do texto, tendo como objeto de investigação "a forma física dos livros e manuscritos (papel, tinta, tipografia, leiaute) ou seus preços, publicidade e mecanismos de distribuição”. ${ }^{24}$ Apesar de investigar assuntos semelhantes aos de Gérard Genette em Paratextos editoriais, McGann aponta que Genette falha por não considerar, ou não aprofundar, a pesquisa sobre a materialidade do texto:

A distinção texto/paratexto pode ser útil para certos fins descritivos, mas para uma investigação mais profunda sobre a natureza da textualidade não é forte o suficiente. Nos últimos seis anos, tenho explorado uma abordagem diferente, chamando a atenção para o texto como uma rede interligada dos códigos linguísticos e bibliográficos. [...] Trata-se, por um lado, de uma distinção que autoriza um estudo mais abrangente da textualidade. A distinção texto/paratexto, como formulada em Paratextos editoriais, não vai, pela própria afirmação de Genette, explorar assuntos como tinta, tipo de letra, papel e vários outros fenômenos cruciais para a compreensão da textualidade. ${ }^{2.5}$

Bonnie Mak credita a D. F. McKenzie e a McGann a importância de se pensar as diversas edições e os atributos gráficos de um texto para legitimar pesquisas no âmbito da literatura e
24. MCGANN. Black riders: the visible language of modernism, p. 12. (Tradução nossa).

25. MCGANN. Black riders: the visible language of modernism, p. 13-14. (Tradução nossa).
EM TESE
BELO HORIZONTE
v. 22
N. 3
SET.-DEZ. 2016
CAMARGO. A forma da letra para o estudo das letras: a condição [ [...]
P. 11-33 
26. MAK. How the page matters, p. 6. (Tradução nossa). de se aprofundar no estudo do modo de produção dos volumes atrelado a questões históricas, estéticas e culturais:

Bibliógrafos e editores textuais, como D.F. McKenzie e Jerome McGann, percebem, no livro impresso, uma prova material do passado e incentivam a pesquisa de "códigos bibliográficos" de determinadas edições e a investigação de histórias sociais ou "sociologias" de textos impressos em que se identificam circunstâncias particulares de sua produção, circulação e recepção. Além disso, a noção complementar de uma "cultura de impressão" introduz e define uma comunidade que pode ser estudada por seus hábitos de leitura e escrita. O "livro impresso" e a "cultura da impressão" foram, assim, circunscritos como entidades aprovadas para investigação acadêmica. Esse reconhecimento disciplinar habilita historiadores e estudiosos literários para entender o livro impresso como um objeto para a exploração do uso e recepção de um texto, e também para justificar o exame de leitores específicos e suas atividades. ${ }^{26}$

Diversas edições de um texto, de manuscritas a eletrônicas, são estudadas por Bonnie Mak, que percebe como diferentes códigos gráficos podem alterar a leitura. Assim, diferentes abordagens de design da página impressa promovem diversas maneiras de leitura e interpretação.
O projeto gráfico de um livro é muitas vezes desenvolvido a partir da tipografia, como se esta fosse o elemento mais importante, pois é a partir dela que a leitura é possível. $\mathrm{McKenzie}^{27}$ analisou as diferenças tipográficas de uma frase em épocas distintas: a primeira original de 1710 e outra de 1946, composta com tipo de estilo diferente do original. Esse estudo mostra que a tipografia, assim como a língua estrita altera-se em diálogo com questões estéticas de cada época, e como o texto em sua formatação original pode comunicar dados a respeito do contexto da escritura.

Para a maioria dos autores do campo da literatura, a materialidade versa, é claro, sobre a importância do estudo do suporte físico como auxiliar da análise textual. Nesse campo, parece ser importante usar como objeto de estudo não apenas livros graficamente elaborados, mas toda e qualquer edição de um texto. A pesquisa de McKenzie ${ }^{28}$ parece apontar para o caminho do estudo especialmente da tipografia, mas em seu texto ainda parecem faltar diretrizes visuais para tal análise. A partir da percepção dessa lacuna no campo da análise textual, apresentam-se aqui, mesmo que de forma resumida, algumas informações relevantes para a análise material da página impressa.

\section{ANATOMIA E ESTÉTICA TIPOGRÁFICA}

A aparência de uma fonte tipográfica é fruto dos recursos tecnológicos do seu tempo, apesar de que estilos tipográficos
27. MCKENZIE. Bibliografia y sociología de los textos.

28. MCKENZIE. Bibliografia y sociología de los textos.

BELO HORIZONTE

v. 22

N. 3

SET.-DEz. 2016

CAMARGO. A forma da letra para o estudo das letras: a condição [...]

P. 11-33 
antigos e clássicos possuem versão digital e ainda, talvez como processo anacrônico, continuam muito utilizados. Hoje, muitos leitores e usuários de informática podem manipular a tipografia digital por meio de um computador. Como aponta Melot, antes apenas os profissionais eram "sensíveis a diferenças estéticas" tipográficas, mas hoje todos são "escribas", todos podem ter acesso à composição tipográfica por meio de um computador pessoal:

Somente os profissionais eram sensíveis a essas diferenças estéticas. Hoje, a banalização das práticas tipográficas graças aos computadores pessoais torna o escriba muito mais consciente da dimensão estética que se deve levar em conta. Como no manuscrito, o computador convida o leitor a se comportar como um escriba e as duas funções acabam por se confundir. ${ }^{29}$

Se por um lado é bastante positiva a popularização da tipografia pelo meio digital, por outro isso mostra o quanto é necessário dar não apenas a ferramenta, mas também a instrumentalização teórica e técnica necessária para seu uso. Um dos softwares mais utilizados para a escrita digital é o Microsoft Word, que infelizmente pode criar certos preconceitos estéticos da tipografia. A partir de levantamento empírico, ao se perguntar a diversos usuários do software o que é, por exemplo, a tipografia itálica, a maioria vai dizer que é a letra "normal" inclinada. O "normal" seria o alfabeto romano. O itálico não é e nunca será uma romana inclinada. Existem romanas oblíquas, ou seja, inclinadas, mas estas não são itálicas. Em tipografia o itálico é um novo e diferente alfabeto. As itálicas possuem estruturas diferentes das romanas, sendo cursivas. As serifas das itálicas são transitivas, unilateriais e sugerem continuidade, enquanto as serifas das romanas são intransitivas e bilaterais (Figura 2). As itálicas são sim inclinadas, embora esta não seja sua única característica. O Word pode induzir ao erro ao "italizar", isto é, inclinar qualquer tipografia, mesmo que esta não possua versão itálica.

\section{$\mathrm{i} \mathrm{i}$ \\ $i 1=a \mathrm{a}=$ \\ transitiva intransitiva \\ intransitiva intransitiva}

Pode-se enumerar uma série de outros problemas que a ferramenta sugere, mas este é de longe o que mais chama a atenção e o que mais confunde os usuários. Assim, mesmo 
30. Apesar de a tipografia ser muito relevante na maioria dos livros, naqueles ricamente ilustrados ela muitas vezes fica em segundo plano. O livro em prosa é essencialmente tipográfico, pois há poucos elementos gráficos além do texto.

que a grande maioria seja consciente da importância da tipografia, poucos são sensíveis a suas características estéticas.

Talvez a maioria dos leitores perceba a diferença elementar entre uma fonte com ou sem serifa e associe o uso de tipos serifados ao livro impresso e o uso dos sem serifa a suportes digitais como a tela do computador, do celular ou do tablet. No entanto, essa divisão não é suficiente para quem estuda tipografia ou design editorial. Existe grande variedade forma entre tipos serifados (Figura 3) e sem serifa, suficientes para que fossem criados desde o final do século XIX e especialmente no XX dezenas de propostas de classificação tipográfica a partir de características estéticas e históricas.

Alguns autores defendem pensar a tipografia em duas escalas, a micro e a macro. Tipografia não designa somente a forma ou o design do tipo, mas especialmente todo projeto de design no qual a tipografia é o elemento fundamental, como no caso do design editorial, especialmente o de livros em prosa. ${ }^{30}$ Microtipografia relaciona-se ao desenho dos tipos e a detalhes relativos às letras, como espaços entre letras e

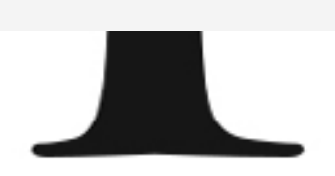

Serifa triangular de base irregular e junçð̃es irregulares de Trajan

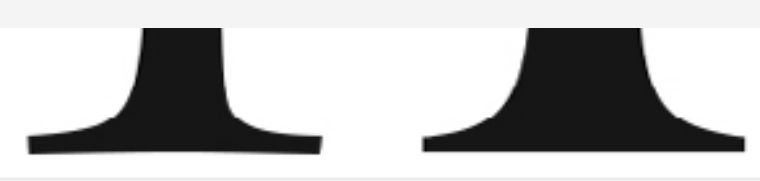

Serifa triangular de. ase regular e junçōe regulares de Baskerville palavras, entrelinhas, ajustes óticos, etc. Já a macrotipografia refere-se ao leiaute geral do suporte e de escolhas materiais e de produção. Hochuli e Kinross assinalam:

O designer de livro preocupa-se com as seguintes questões específicas: formato, extensão, tipografia (estes três, em parte, determinam uns aos outros); materiais (papéis, materiais de encadernação); reprodução; impressão; acabamento. Aqui lidamos principalmente com a tipografia e, dentro desta categoria, nos assuntos que fazem parte do que pode se chamar macrotipografia. Microtipografia ou tipografia de detalhe lida com os seguintes itens: forma das letras, espaços entre letras e palavras, espaços entre linhas e coluna. ${ }^{31}$

A macrotipografia refere-se ao projeto como um todo: definição de formato da página, tamanho das colunas, distribuição das ilustrações, a organização dos títulos e legendas e todos os outros elementos tipográficos. Portanto, tudo que se relaciona aos detalhes tipográficos, como a forma das letras e suas

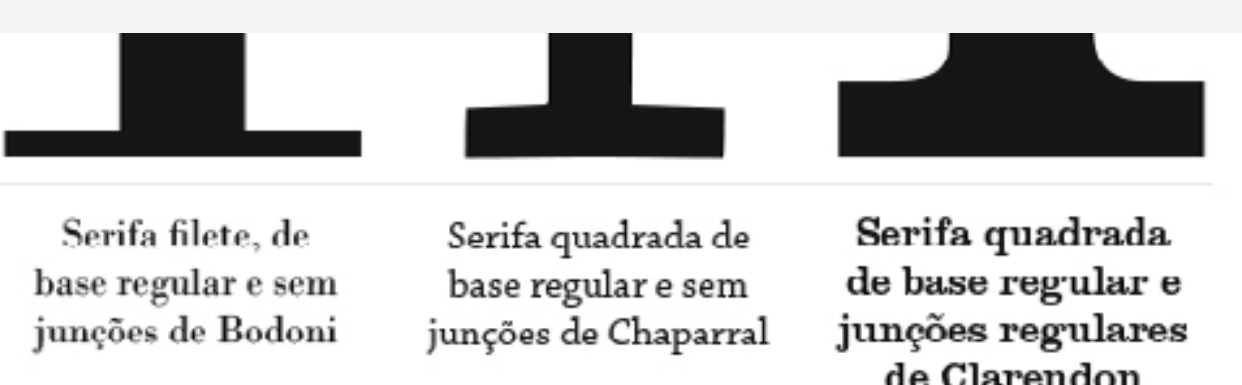

31. HOCHULI, KINROSS. Designing (Tradução nossa). 
32. KUNZ. Typography: macro + micro aesthetics, p. 97. (Tradução nossa).

33. UNGER. While you're reading, $\mathrm{p}$. 85. (Tradução nossa).

34. BRINGHURST. Elementos do estilo tipográfico.

35. HOCHULI. O detalhe na tipografia. relações espaciais, encontra-se no domínio da microtipografia e o projeto gráfico, ou design, no domínio da macrotipografia.

O design tipográfico "inevitavelmente expressa emoções subjetivas e comunicativas que afetam a percepção", que pode ser explícita e óbvia (macro) ou sutil e sofisticada (micro), explica Willi Kunz. ${ }^{32}$ Além do impacto da percepção visual, Gerard Unger defende que a leitura depende não apenas dos tipos individuais, mas especialmente da composição como um todo e ainda que: "A facilidade de leitura, na medida em que consideramos a leitura de um texto em particular irritante ou fácil, depende tanto da microtipografia como da macrotipografia". ${ }^{33}$

Há uma série de questões que envolvem as boas práticas da composição de um texto em relação à microestética ou à microtipografia, especialmente quando se trabalha com a diagramação de um texto. Autores como Bringhurst ${ }^{34}$ e Hochuli ${ }^{35}$ são defensores do rigor da tipografia de detalhe para um leiaute de qualidade, que é consequentemente pragmática, já que a boa qualidade da composição interfere, obviamente, na qualidade da leitura. Quando se observam letras em uma coluna de texto, talvez sejam pouco evidentes atributos e diferenças formais, mas a tipografia comunica, todo desenho de qualquer conjunto de caracteres alfabéticos possui significados contextuais e formais inerentes e tais significados podem ser complementares ao texto composto por esse conjunto.
Para Marshall Lee, as faces tipográficas para uso em texto apresentam muita variação formal nem sempre notada, pois os tipos são vistos em corpos pequenos. No entanto, mesmo que os leitores não percebam "as distintas características de um tipo para texto, eles podem ser afetados por elas" ${ }^{36}$ Certos atributos formais de uma fonte podem sugerir qualidades como força, delicadeza, leveza, etc:

uma das diferenças mais perceptíveis em faces tipográficas são seus níveis de força e delicadeza. Alguns tipos são definitivamente fortes e robustos, outros são claramente leves e delicados, alguns estão no meio-termo. Embora aqui, como em outras classificações de caráter, possam existir diferenças de opinião, é razoavelmente seguro dizer que quase todo mundo consideraria as fontes Caledônia, Times Roman e Monticello relativamente fortes; Granjon, Weiss, e Bodoni Book, relativamente delicadas. Mas, em todos os casos, a sensação transmitida pelo tipo depende em parte da forma como é usado. ${ }^{37}$

\section{ESTUDO DE CASO: QUATRO DESIGNS DE UM MESMO}

\section{TEXTO}

Ilustrações e ornamentos gráficos chamam a atenção para a página impressa e podem estabelecer relações com o texto do volume e comunicar informações estéticas e culturais do período em que o volume foi produzido. No entanto, a superfície
36. LEE. Bookmaking: editing, design, production, p. 117. (Tradução nossa).

37. LEE. Bookmaking: editing, design, production, p. 117. (Tradução nossa). 
da página do livro é marcada pelo grafismo que o próprio texto produz, ou seja, por sua tipografia. Se o leiaute como um todo pode sensibilizar de forma mais efetiva o leitor para a estética da página, a forma e detalhes sutis podem mudar completamente o visual da página. Na década de 1940, a Associação dos Designers Gráficos Americanos, a AIGA (American Institute of Graphic Arts), procurou evidenciar sutilezas das diferenças de projetos gráficos de livros a partir de visões, opiniões e
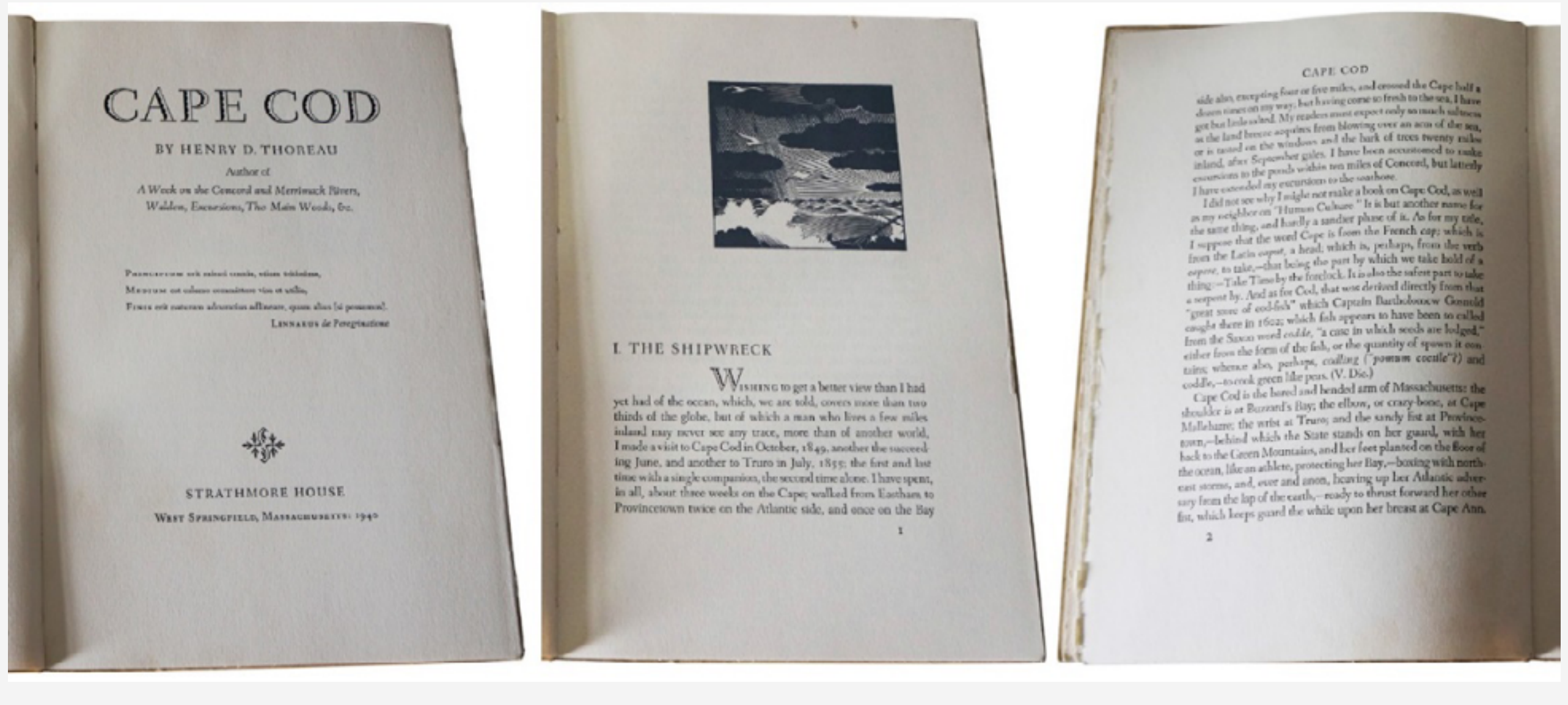

EM TESE

BELO HORIZONTE

v. 22

N. 3

SET.-DEZ. 2016

CAMARGO. A forma da letra para 0 estudo das letras: a condição [...]

P. $11-33$
38. Utilizou-se aqui a palavra "folheto" com base na definição de Frederico Porta (1958, p. 160) em seu dicionário de artes gráficas, em que folheto consiste em uma "obra de poucas folhas menor que um livro". O folheto criado pela associação foi distribuído como lembrança (keepsake) ou presente para seus associados.

39. Cape Cod, de Henry David Thoreau, descreve uma

região praiana no estado de

Massachusetts, na costa leste dos

Estados Unidos. O capítulo inicial,

"Shipwreck, , presente no projeto

das quatro versões, apresenta

o local, a etimologia do nome

dessa regiaao (em que o capitão Bartholomew Gosnold encontrou bacalhau em 1602) e o desastroso acidente com uma embarcação inúmeras mortes. 
capítulo e uma página de texto. Além dos projetos de design, cada designer redigiu uma justificativa.

Designer do primeiro projeto apresentado (Figura 4), Rudolph Ruzicka utilizou sua própria fonte tipográfica Fairfield. A composição foi feita em tipos de corpo 12 e entrelinha de 14 pontos, com alinhamento justificado. O texto foi composto em coluna de tamanho apropriado, cuja largura comporta uma média de 63 caracteres por linha. Essa
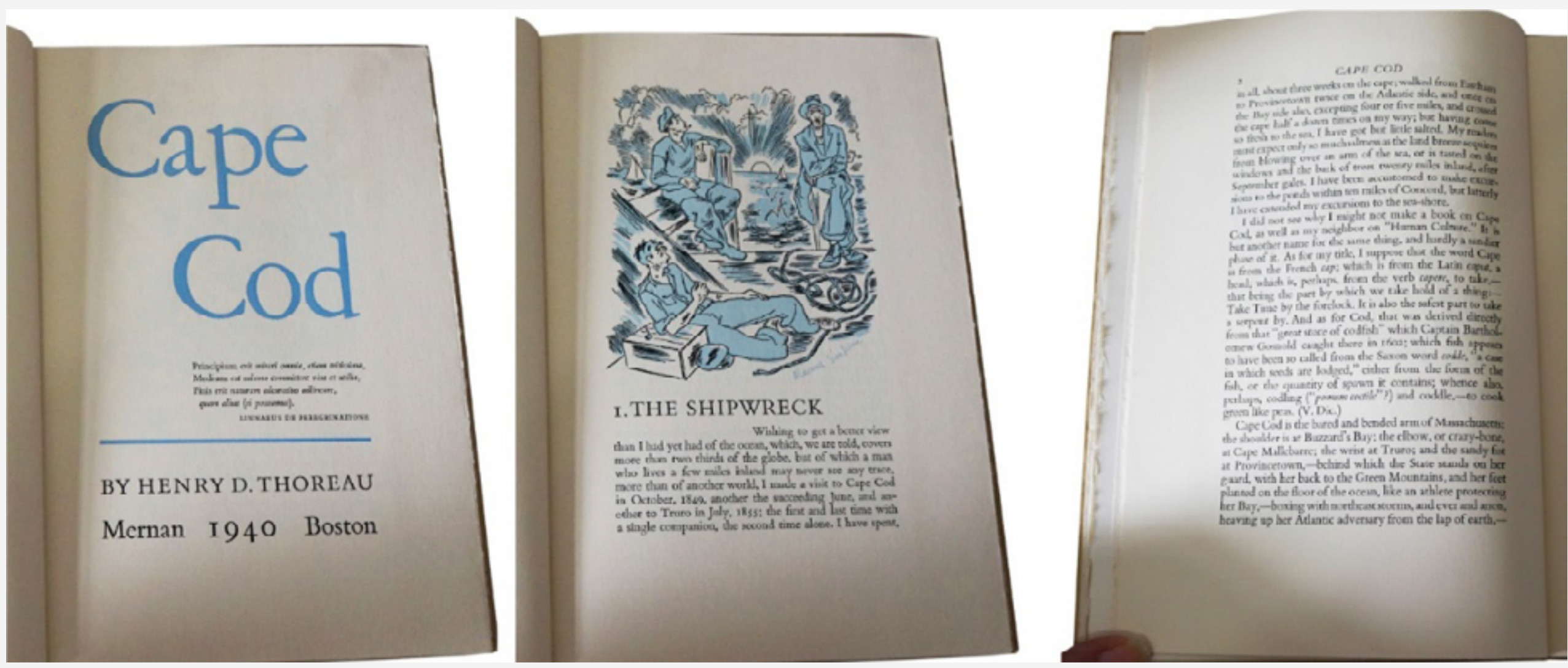
por autores como Bringhurst, ${ }^{40}$ segundo o qual a média de caracteres por linha é muito importante para a legibilidade e colunas estreitas de texto justificado, em geral com menos de 50 caracteres por linha, apresentam buracos ("caminhos de rato"). Em contrapartida, colunas muito largas (mais de 80 carateres) são prejudiciais, pois forçam o olho a se movimentar mais sobre a superfície impressa. A página é arejada por conta das margens generosas do texto e devido à própria
40. BRINGHURST. Elementos do estilo tipográfico. 
41. Essa tipografia foi criada em 1929 pelo tipografo Stanley Morrisson que se inspirou e estudou os tipos criados por Francesco Griffo utilizados por Aldus Manutius para a impressão de De Aetna, de Pietro Bembo, em 1496. No final do século XIX e inicio do século XX houve uma grande produção de tipografias inspiradas ou fielmente baseadas em desenhos clássicos, que convencionou-se chamar de "resgate tipográfico". leveza dos caracteres da Fairfield, com pouco contraste entre traços grossos e finos.

Helen Gentry, responsável pelo segundo projeto (Figura 5 ), explicou que escolheu a fonte Bembo ${ }^{41}$ por não ser nem "seca" nem "barulhenta". O texto foi composto em corpo e entrelinha de 11/13 pontos e a coluna apresenta rendimento médio de 58 caracteres por linha, ou seja, satisfatório para a leitura. A fonte Bembo é de época distinta da em que foi
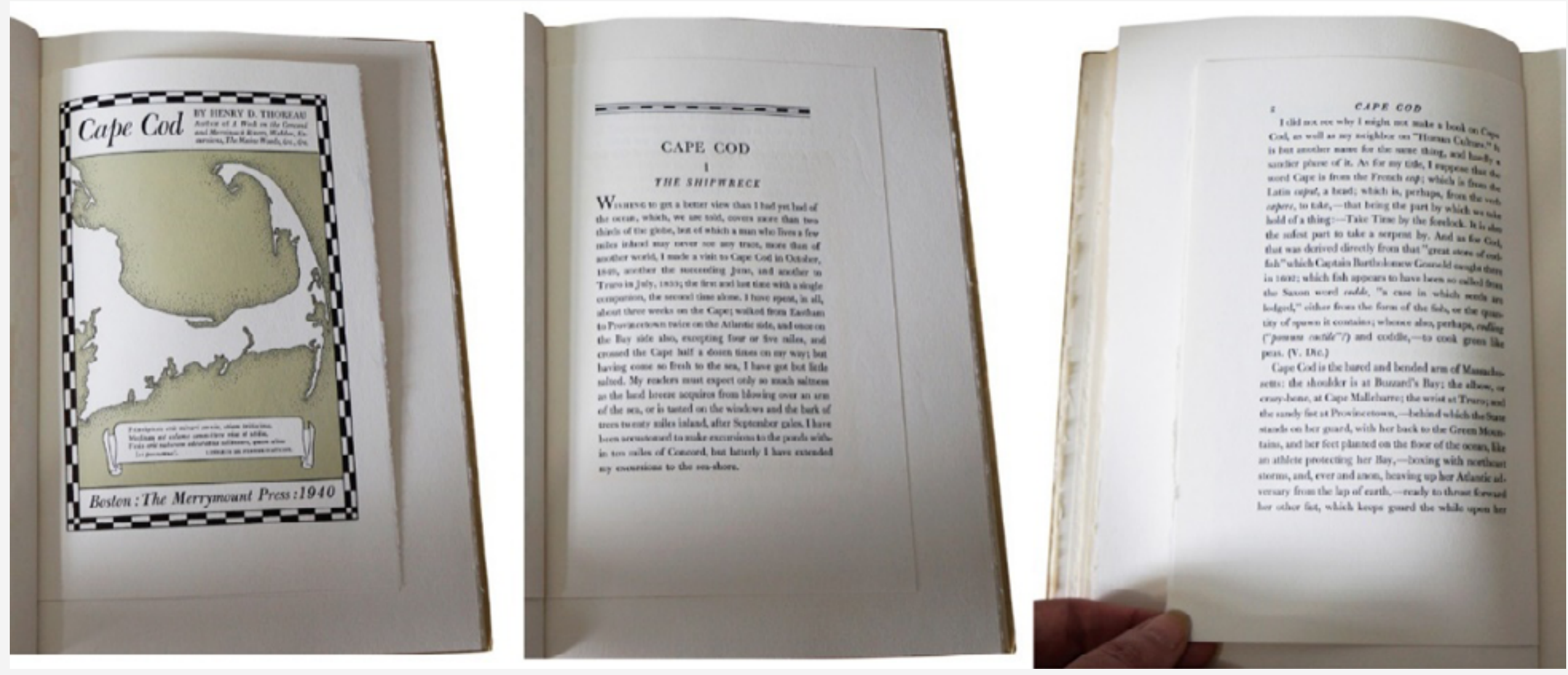
Bulmer é mais escuro (mais denso e contrastado que os tipos usados nas duas propostas anteriores), é provável que o designer tenha utilizado uma entrelinha maior para compensar a tonalidade da mancha gráfica. Era costumeiro também, a partir da tradição criada por Bodoni, quando se usassem tipos chamados modernos (de serifas finas, contraste acentuado e eixo racional), usar entrelinhas maiores do que em tipos oldstyle como Bembo, usados no exemplo anterior.
A última proposta deste folheto é de William A. Kittredge, da Lakeside Press, uma divisão de livros especiais da editora R.R. Donnelley \& Sons Company, em Chicago (Figura 7). Neste exemplo, o texto foi composto em Scotch Roman em corpo 12 e entrelinha de 16 pontos. As entrelinhas e margens generosas provavelmente foram escolhidas para equilibrar a densidade do peso do tipo, que apresenta contraste acentuado entre traços finos e grossos.
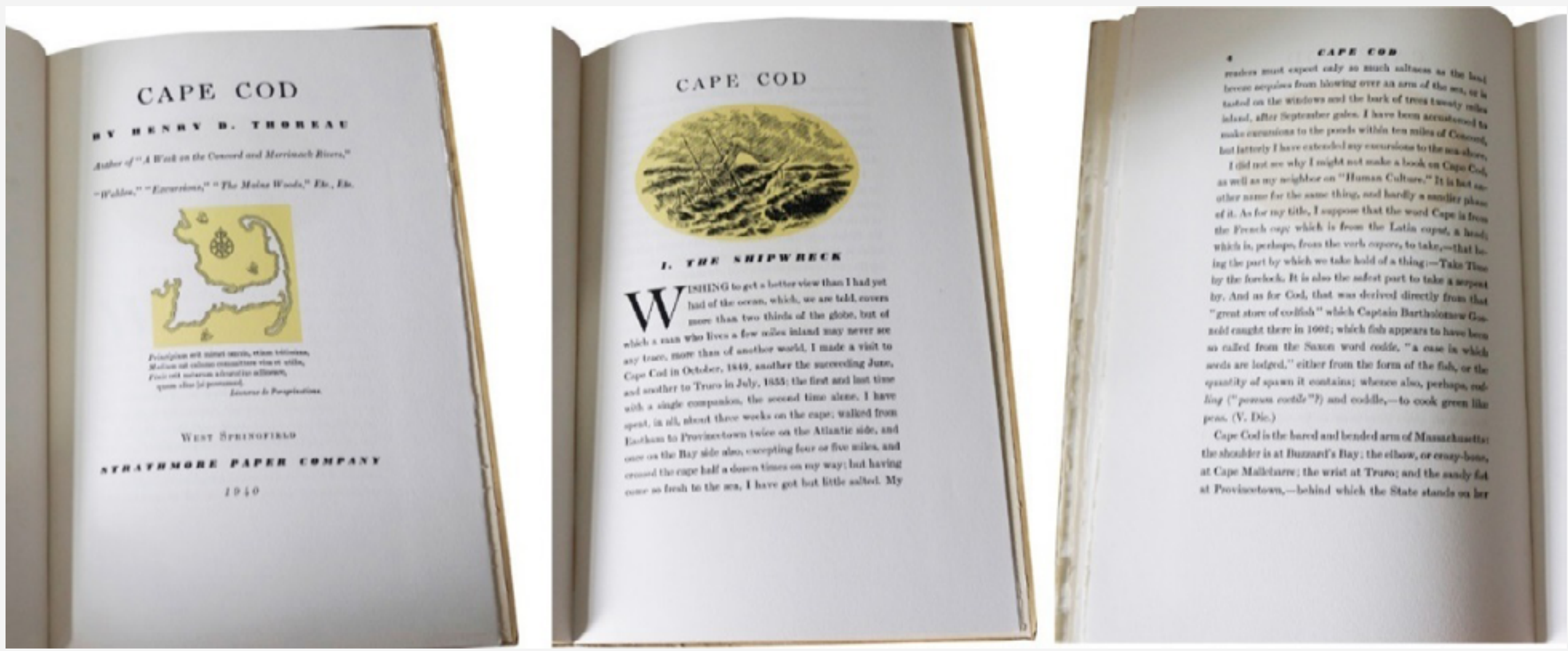

EM TESE

BELO HORIZONTE

v. 22

N. 3

SET.-DEZ. 2016

CAMARGO. A forma da letra para o estudo das letras: a condição [... ]

P. $11-33$ 
FIGURA 8 - Comparação entre as tipografias: 1, Fairfield; 2 Bembo; 3 Bulmer; 4 Scotch Roman
É possível perceber nos exemplos como cada solução é uma interpretação do designer sobre o texto. Ruzicka e Gentry escolheram tipos para a composição do corpo do texto mais leves, e Updike e Kittredge, tipos mais pesados,

I have been accustomed to make wh ten miles of Concord, but latterly ursions to the seashore.

ght not make a book on Cape Cod, as well man Culture." It is but another name for dly a sandier phase of it. As for my title, 1 Cape is from the French cap; which is head; which is, perhaps, from the verb id not see why I might not make a book on Cape
as 3 as my neighbor on "Human Culture," anotner name for the same thing, and hardly $r$ phase of it. As for my title, I suppose that the Cape is from the French cap; which is from the capul, a head; which is, perhaps, from the verb , to take, - that being the part by which we take if a thing:- Take Time by the forelock. It is alo mais contrastados e expressivos, talvez para conotar tensão e peso. Os tipos usados pelos dois últimos são da época em que o texto foi escrito, século XIX, ou seja, estas escolhas apresentam alusão histórica e relacionam-se, de certa forma,

(ne the sea, I have got but ntue sa pect only so much saltness as the lar blowing over an arm of the sea, o frows and the bark of trees twenty $\mathrm{m}$ September gales. I have been accustomec septe the ponds within ten miles of Con stons to the peaI did not see why I might not make 1 suell as mv neighbor on "Huma ders must expect only so much salt acquires from blowing over an arr tasted on the windows and the bark of $\mathrm{tr}$ inland, after September gales. I have bee make excursions to the ponds within ten $r$ but latterly I have extended my excursions I did not see why I might not make a bo 
com o conteúdo pelo período histórico. Apesar de Kittredge e Updike terem escolhido esses tipos mais pesados, compensaram isso com o uso de uma entrelinha maior para favorecer a legibilidade.

Esses exemplos criados para o folheto da AIGA mostram a preocupação dessa associação em promover o design editoria na época e, ao selecionar quatro reconhecidos designers para criar projetos gráficos diferentes de páginas de um livro em prosa, de certa forma apontam que a simples mudança da fonte é uma mudança estética substancial, pois os diferentes desenhos desses tipos podem transmitir mensagens diversas (Figura 8). Supõe-se que os designers devem ter escolhido a tipografia e os demais elementos gráficos de forma a cria uma atmosfera densa ou suave para o texto. Mesmo que as páginas de texto sejam parecidas, se comparadas às páginas de abertura ou às de rosto, a escolha da tipografia, a composição da mancha das quatro edições têm densidades, tons e pesos diferentes. Mesmo alterações aparentemente "sutis" podem ter impacto, suas “entonações” visuais são diferentes, assim como diferentes atores ou diretores teatrais dão diferentes interpretações a um mesmo texto.

\section{UMA BREVE CRÍTICA}

A tipografia, obviamente, tem a função utilitária de proporcionar a escrita e a leitura. Autores como Flávio Cauduro, no entanto, consideram ultrapassada a visão meramente funcional. Cauduro associa a abordagem da tipografia como "auxiliar" da linguagem a uma visão da linguística estruturalista de Saussure, em que a escrita é "auxiliar" na representação da linguagem falada.

Para ele, esse posicionamento da linguística, que ele acredita estar associado a uma ideologia funcionalista do design de livros, está intimamente relacionado ao design "simples" de livros sérios, como se pode observar na passagem a seguir:

Não é de se admirar, portanto, que a escrita linear interrompida, não-ilustrada, monotonamente "cinza", tenha se tornado a norma e o ideal tipográfico dos chamados livros "sérios", numa tentativa fútil de impressores e editores de torná-la uma representação neutra e tão fiel quanto possível à "fala original” e aos significados pretendidos por seus autores. ${ }^{42}$

Muitos defendem a tipografia funcional e, consequentemente, o livro funcional, mero suporte para um texto. Para Megan Benton, ${ }^{43}$ o descaso com o design e a forma do livro cria-se a partir de uma suposta separação entre a forma e o conteúdo, entre o objeto e o texto que ele guarda. Hendel também critica o meio editorial por seu pouco apreço pelo design:
42. CAUDURO. Desconstrução e tipografia digital, p. 87.

43. BENTON. The beauty and the book, p. viii. (Tradução nossa) 
45. SPIEKERMANN. $A$ linguagem invisível da tipografia, p. 77.

46. BARTRAM. Making books: design in British publishing since 1945, p. 9-10. (Tradução nossa).
Algumas editoras não têm qualquer conhecimento do design de livro. Preocupam-se apenas em colocar o máximo possível de letras numa página. A falta de estilo ou de elegância de seus livros é tamanha que só posso presumir que nenhum designer sequer chegou perto dos livros que publicam. ${ }^{4}$

Há no mercado editorial hoje um grande apreço pelo design da capa, pois é ela que vende o livro, mas um baixo investimento no miolo, como observa Spiekermann:

A maneira como os livros são lidos não se alterou muito nos últimos 500 anos, portanto o aspecto dos livros não teve que mudar também. Apenas a economia mudou, o que significa que os editores de hoje insistem em colocar cada vez mais texto na página e nem sempre estão preparados para pagar por uma boa composição, exceto aqueles que realmente se preocupam com o design interno de um livro e não apenas com a capa. ${ }^{45}$

Houve obviamente uma inversão funcional, pois a capa antes servia para proteger e agora ela é a embalagem marqueteira do conteúdo. Se o mercado editorial estivesse mais preocupado com a qualidade do produto como um todo, valorizaria mais o design do miolo. Hoje, como aponta Bartram, perdeu-se de certa forma a "inocência no mundo da edição". ${ }^{46}$ O autor afirma que atualmente muitas editoras são "grandes negócios" e lamenta que muitos editores ainda não percebam a diferença entre um bom projeto de livro de texto:

Infelizmente, muitos editores de hoje, bons editores que publicam livros de valor, são incapazes de ver a diferença entre um livro de texto bem composto e legível de um texto mal composto, porém ainda legível. Eles aprenderam apenas a metade do seu negócio. Desconforto e até mesmo às vezes a ilegibilidade afastam o prazer. ${ }^{47}$

Um texto pode muitas vezes possuir uma versão mais barata e outra mais cara e especial, que apontam também para diferenças entre tipos de leitor: aquele que quer apenas consumir o conteúdo e aquele que além de ler valoriza a qualidade física do objeto. A brochura, a edição de bolso, além de muitas vezes ser produzida com materiais e processos inferiores em comparação à de capa dura, pode também ter um design de má qualidade que prejudica, especialmente, a fluência da leitura ou leiturabilidade (readability). Os fatores que influenciam na leiturabilidade são desenho do tipo, corpo, espaço entre letras e palavras, entrelinhas, largura da coluna, margens e tom do papel. A questão da leiturabilidade também confere valor à obra, já que livros que não atingem critérios mínimos de conforto visual podem ser abandonados. Mesmo aqueles de boa qualidade material, costurados
47. BARTRAM. Making books: design in British publishing since 1945, $\mathrm{p}$. 11. (Tradução nossa). 
48. Nesse contexto, em relação ao cas páginas, da mancha de texto.

49. CHARTIER. $A$ aventura do livro: do leitor ao navegador, p. 16.

50. MELOT. Livro,, p. 25-35.

e com papel de boa qualidade podem ter projeto gráfico de miolo de baixa qualidade. ${ }^{48}$

Há cerca de uma década, autores como Roger Chartier e Jean Lebrun passaram a investigar a suposta crise do suporte livro impresso, com o advento do livro eletrônico, mas eles não acreditam nas ideias apocalíticas de que o impresso deixará de existir, principalmente por suas qualidades físicas, pela função de coleção e pela proximidade com o leitor, como Jean Lebrun afirma em entrevista ao próprio Chartier. ${ }^{49}$ "O texto eletrônico torna possível uma relação muito mais distanciada, não corporal."

Em seu ensaio Livro, ${ }^{50}$ Michel Melot justifica a existência do impresso por sua forma física e autônoma. Nesse ensaio, o autor defende o livro como algo que não deve ser pensado apenas como um suporte subordinado a um texto. Este pode ser escrito ou reproduzido em diversos suportes, inclusive os eletrônicos, mas o livro é um objeto que existe por sua forma, independentemente de ter um texto verbal ou não.

Charlotte Rivers explica que por um tempo acreditou que os novos suportes, como tablets, iPads e mesmo aplicativos para celulares, poderiam criar uma significativa crise no mercado do impresso. No entanto, "a venda dos livros continua a crescer ano a ano e seu formato se tornou um antídoto necessário a um mundo cada vez mais impulsionado pela

tecnologia". ${ }^{51}$ Dessa maneira, é a materialidade do livro e sua estética, ou seja, os diferenciais do impresso frente ao digital, que o manterão "vivo".

Recentemente, Adrian Shaughnessy ${ }^{52}$ escreveu ao Design Observer que é justamente a ameaça do livro eletrônico que tem impulsionado a ideia do livro como objeto material e, por isso, provavelmente o impresso se perpetuará: "Eu argumento que as publicações eletrônicas fracassam em estabelecer uma alternativa emocionalmente satisfatória ao livro impresso e têm realçado seu status material". Além da importância da questão material, outra bastante levantada pelos designers é a de o designer procurar se familiarizar cada vez mais com o conteúdo textual com que irá trabalhar.

Haluch $^{53}$ defende, em seu guia editorial, a importância de os designers conhecerem com profundidade o texto do livro, para que o projeto se adeque a ele:

Dependendo do livro, é essencial lê-lo todo - no caso de um romance, por exemplo. Em outros casos - livros técnicos, instrumentais etc. - com o sumário, a introdução e o primeiro capítulo já temos noção do que se trata aquele livro. ${ }^{54}$

Na maioria das vezes, a editora prevê prazos muito curtos para a execução do livro, o que nem sempre permite ao designer realizar uma leitura atenta do original e nem mesmo uma
51. RIVERS. Book-Art: innovation in book design, p. 8. (Tradução nossa).

52. SHAUGHNESSY, Books. Still not

53. HALUCH. Guia prático de design editorial: criando livros completos,

54. HALUCH. Guia prático de design editorial: criando livros completos, p. 29. 
55. HALUCH. Guia prático de design editorial: criando livros completos. reflexão sobre o texto que possibilite algum tipo de pesquisa e interpretação do conteúdo, mas esta pode ser uma atitude que auxilia sobremaneira o processo criativo.

\section{CONSIDERAÇÕES FINAIS}

A partir do que foi apresentado acima, percebe-se que a tipografia, mesmo que discreta, ao "materializar" o conteúdo textual, pode transmitir outros significados através de sua forma e contexto histórico e cultural.

Hoje, um texto não é apenas criado pelo autor, há muitas pessoas na cadeia de produção de um livro, como editores, preparadores, revisores, designers, ilustradores, diagramadores, produtores gráficos, e todos eles, ao colaborarem para uma edição, criam os paratextos do volume, e assim, pelas correntes teóricas contemporâneas, participam de alguma forma da autoria daquela obra. Se o designer é também de alguma forma autor, não deveria também se aprofundar no estudo de literatura, ou ao desenvolver um projeto conhecer bem o conteúdo textual, como apontou Haluch ${ }^{55}$

Para o autor de um texto, conhecimentos aprofundados de tipografia podem ser muito úteis para sua própria criação literária. A partir deste estudo, buscamos mostrar como o estudo do design e da tipografia podem ser úteis para o campo da análise textual, bem como é importante para o campo do design conhecer em profundidade a literatura. Designers familiarizados com o campo das letras provavelmente podem criar projetos que não sejam apenas adequados para a leitura, mas também que possam estabelecer relações semânticas com o texto. Assim, se texto e design estiverem em maior sintonia, talvez vejamos mais pesquisas produzidas no campo da literatura sobre a condição paratextual do design e da tipografia.

\section{REFERÊNCIAS}

BARTRAM, Alan. Bauhaus, modernism and the illustrated

book. New Haven: Yale University Press, 2004.

BARTRAM, Alan. Five hundred years of book design. New Haven: Yale University Press, 2001

BARTRAM, Alan. Making books: design in British publishing since 1945. New Castle: Oak Knoll Press, 1999.

BENTON, Megan L. Beauty and the book: fine editions and cultural distinction in America. New Haven; London: Yale University Press, 2000

BRINGHURST, Robert. Elementos do estilo tipográfico. São Paulo: Cosac Naify, 2005

BRINGHURST, Robert. A forma sólida da linguagem. Tradução de Juliana A. Saad. São Paulo: Rosari, 2006. 
CAMARGO, lara Pierro de. 0 livro de literatura: entre o design visível e o invisível. 2016. 348 p. Tese (Doutorado) - Faculdade de Arquitetura e Urbanismo, Universidade de São Paulo, São Paulo, 2016.

CAMARGO, lara Pierro de; "O Paradigma do design do livro "invisível", p. 720-732 . In: Anais do 120 Congresso Brasileiro de Pesquisa e Desenvolvimento em Design [Blucher Design Proceedings, v. 9, n. 2]. São Paulo: Blucher, 2016.

CAUDURO, Flávio Vinicíus. Desconstrução e tipografia digital. Arcos Design, Rio de Janeiro, v. 1, p. 76-101, 1998.

CHAPPELL, Warren; BRINGHURST, Robert. A short history of the printed word. Vancouver: Hartley \& Marks, 1999.

CHARTIER, Roger. A aventura do livro: do leitor ao navegador. Conversações com Jean Lebrun. São Paulo: Editora Unesp, 1998.

GENETTE, Gérard. Paratextos editoriais. São Paulo: Ateliê Editorial, 2009

HALUCH, Aline. Guia prático de design editorial: criando livros completos. Teresópolis: 2AB, 2013.

HENDEL, Richard O design do livro Tradução Geraldo Gerson de Souza e Lúcio Manfredi São Paulo: Ateliê Editorial 2006.

HOCHULI, Jost. $\mathbf{O}$ detalhe na tipografia. Tradução de Karina Jannini. São Paulo: WMF Martins Fontes, 2013.

HOCHULI, Jost; KINROSS, Robin. Designing books: practice and theory. London: Hyphen Press, 2007.
KUNZ, Willi. Typography: macro + micro aesthetics. Zurich: Verlag Niggli, 2002

LEE, Marshal. Bookmaking: editing, design, production. $3^{\text {rd }}$ ed New York: WW Norton \& Company, 2004.

LYONS, Martyn. Livro: uma história viva. Tradução de Luís Carlos Borges. São Paulo: Editora Senac, 2011.

LOMMEN, Mathieu et al. The book of books: 500 years of graphic innovation. London: Thames \& Hudson, 2012

MAK, Bonnie. How the page matters. Toronto: University of Toronto Press, 2011

MANGUEL, Alberto. Uma história da leitura. Tradução de Pedro Maria Soares. São Paulo: Companhia das Letras, 1996.

McGANN, Jerome J. The textual condition. New Jersey: Princeton University Press, 1991

McGANN, Jerome J. Black Riders: the visible vanguage of modernism. New Jersey: Princeton University Press, 1993.

MCKENZIE. D. F. Bibliografía y sociología de los textos. Prólogo de Roger Chartier. Traducción de Fernando Bouza. Madrid: Ediciones Akal, 2005.

MELOT, Michel. Livro,. São Paulo: Ateliê Editorial, 2012.

MIDDENDORP, Jan. Shaping text. Amsterdam: Bis, 2012 
PORTA, Frederico. Dicionário de artes gráficas. Porto Alegre:

Editora Globo, 1958

RIVERS, Charlotte. Book-Art: innovation in book design.

Switzerland: Rotovision, 2009.

SHAUGHNESSY, Adrian. Books. Still not dead. Design Observer, Jan. 2016. Disponível em: <https://goo.gl/fKuu1d>. Acesso em:

12 dez. 2016.

SPIEKERMANN, Erik. A linguagem invisível da tipografia Tradução de Luciano Cardinali. São Paulo: Blucher, 2011.

UNGER, Gerard. While you're reading. New York: Mark Batty, 2007 